pound heterozygous for the $621+1 \mathrm{G} \rightarrow \mathrm{T}$ and the $711+1 \mathrm{G} \rightarrow \mathrm{T}$ mutations. Clin Genet (in press).

8 Kristidis P, Bozon D, Corey M, et al. Genetic determination of exocrine pancreatic function 1178-84.

9 The Cystic Fibrosis Genotype-Phenotype Consortium. Correlation between genotype and phenotype in cystic fibrosis: analysis of and phenotype in cystic fibrosis: analysis of seven common

10 De Braekeleer M, Daigneault J, Aubin G, et al. Phenotypic heterogeneity in CF sibs compound heterozygous for the G85E an $621+1 \mathrm{G} \rightarrow \mathrm{T}$ mutations. Clin Genet 1995;47 110-11. L. Two CF patients: one homozygous for the R553X stop mutation, the other homozygous for the $621+1 \mathrm{G} \rightarrow \mathrm{T}$ mutation. XIth International Cystic Fibrosis Congress,Dublin 1992;1 MP95.

12 Cheadle JP, Meredith AL, Millar-Jones L Goodchild MC. Two CF patients, one homozygous for the $621+1 \mathrm{G} \rightarrow \mathrm{T}$ splice mutation splice mutation. $\mathcal{F}$ Med Genet 1995;32:158.

13 Witt M, Pogorzelski A, Zebrak J, Rutkiewicz E. A cystic fibrosis patient homozygous for $621+1 \mathrm{G} \rightarrow \mathrm{T}$ mutation has severe pulmonary disease, mild pancreatic insufficiency and gastro-esop

\section{A new cytofluorometric approach to detect fetal cells in the maternal circulation}

Fetal trophoblasts, lymphocytes, and erythrocytes are present in the peripheral blood of women during pregnancy. Since they are a potential source of material for prenatal diagnosis of fetal inherited disorders, several different procedures have been described to detect or enrich these fetal cells. However, there is a problem because of the scarcity of fetal cells in the maternal circulation. ${ }^{1-3}$

A comparable problem is the detection of leukaemic cells in bone marrow or peripheral blood samples of potential leukaemia patients. We have recently established a new cytofluorometric assay for the simultaneous measurement of DNA content and intracellular thymidine kinase (TK) activity. ${ }^{45}$ In this assay the cells are incubated with the fluorescent thymidine analogue $\mathrm{N}$-dansyl-amino-uracil-deoxyribose (AUdR DANS), which we have shown earlier to be a in cystic fibrosis. Am $\mathcal{f}$ Hum Genet 1992;50

11 Cheadle J, Al-Jader L, Goodchild M, Meredith the other homozygous for the $1898+1 \mathrm{G} \rightarrow \mathrm{A}$

substrate for TK. The amount of intracellular accumulation of this analogue reflects the TK activity of the cells analysed. After staining of the DNA with ethidium bromide, we detect both fluorescences on a flow cytometer (for the protocol of synthesis and purification of the fluorescent thymidine analogue and for details of the cytofluorometric method see references 4 and 5). Using this assay we have previously shown that normal adult peripheral blood cells do not exhibit TK activity, whereas transformed cells, such as leukaemic cells for example, express high levels of TK activity. This enabled us to detect cytofluorometrically the neoplastic cells in a high excess of normal cells because of their high TK activity. ${ }^{6}$ Recently, we successsfully used this approach specifically to detect leukaemic cells in bone marrow or peripheral blood samples of leukaemia patients. ${ }^{8}$

Using this cytofluorometric assay, we analysed cell samples from patients at different gestational ages undergoing chorionic villus sampling or isolation of fetal umbilical cord blood for standard obstetric indications. These cells were directly analysed without previous cultivation. Nucleated cells from peripheral blood samples were obtained by densitiy gradient centrifugation on FicollPaque. The blood was mixed with phosphate buffered saline in a tube at the bottom of which Ficoll-Paque was gently layered. After centrifugation, the cells at the interface between the plasma and the red cells were collected and analysed. ${ }^{8}$ Permission to use parts of the material obtained for the present study was obtained from the institutional review board. We found that primary fetal trophoblasts and fetal cord blood cells express high levels of intracellular TK activity, whereas adult peripheral blood samples do not contain any detectable TK activity (fig 1). The percentage of TK positive cells in relation to the total number of cells used for the FACS analysis (calculated by cell counting) was about $85 \%$ in the trophoblast samples and between $55 \%$ and $70 \%$ in the fetal cord blood samples. These data have been confirmed by measuring TK activity with the traditional radioactive enzyme assay (for details of this assay see reference 6, data not shown). This observation prompted us to speculate whether it would be possible to

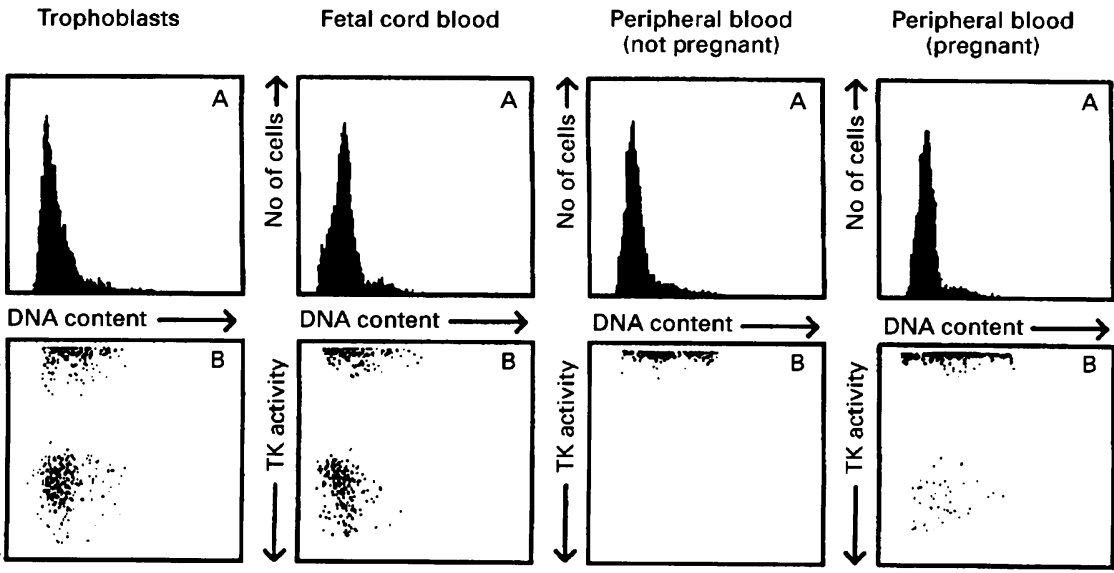

Figure 1 Simultaneous cytofluorometric detection of DNA content and thymidine kinase activity in living cells. About 10000 primary trophoblasts and 30000 fetal cord blood cells were cytofluorometrically analysed as described in the text. In the case of adult peripheral blood of a non-pregnant and a 12 week pregnant woman, about 30000 cells were analysed for DNA distribution and about 40 million lymphocytes were analysed for TK activity. $(A)$ Distribution of DNA content in relation to the number of cells. (B) Two dimensional presentation of DNA content (abcissa) against thymidine kinase (TK) activity (ordinate, note that increasing enzyme activity goes down the axis). detect fetal cells in the circulation of pregnant women using this assay.

When we analysed peripheral blood samples from six different pregnant women we always observed a second cell population with higher intracellular TK activity (fig 1). Since this second cell population was never detected in blood of non-pregnant women or male patients (we have analysed over 30 different blood samples ${ }^{8}$ ), we concluded that this cell population with higher TK activity is very likely of fetal origin. Here it is important to note that in peripheral blood samples we cytofluorometrically analysed about $40 \mathrm{mil}$ lion cells. We first determined this cell number by cell counting on a Coulter counter, then incubated the sample with AUdR DANS, and analysed the whole sample on Partec flow cytometer as described above. ${ }^{4}$ A normal typical flow cytometric measurement contains data from between 10000 to 100000 events for data storage reasons. The analyses described here of such large cell numbers at once were only possible by sequential analysis of DNA distribution and TK activity. For DNA distribution we analysed about 30000 cells; for TK activity (AudR/DANS positive) we analysed about 40 million cells. The latter was possible since only very few cells in the sample were TK positive and accordingly only those appeared on the flow cytometer. All the women analysed were between the 11 th and 13 th week of pregnancy, a time at which the calculated fetal:maternal cell ratio is about 1:400 000 . $^{3}$ These data were in conflict with our earlier observation that the detection limit of our cytofluorometric TK assay varies between 1 cell in 50000 and 1 in 100000 (unpublished results). To investigate whether the sensitivity of detection of fetal cells in maternal blood is higher than 1 in 1000000 or whether the ratio of fetal cells in maternal cells is higher than previously described, we made different dilutions of fetal cord blood cells or trophoblasts in peripheral blood of non-pregnant adults. By this approach we found that our cytofluorometric TK assay indeed enabled us to detect one fetal cell with high TK activity in 400000 maternal cells without detectable TK activity (data not shown)

The data presented here suggest that the second cell population with higher TK activity reflects cells of fetal origin. (1) We show that trophoblasts and fetal cord blood cells express high intracellular levels of TK activity, whereas normal adult peripheral blood is totally TK negative. It has earlier been shown that circulating cells of fetal origin include trophoblasts, fetal lymphocytes, nucleated red blood cells, and haematopoetic stem cells. ${ }^{3}$ (2) The small cell population with high TK activity specifically occurs in peripheral blood samples of pregnant women and not in the circulation of non-pregnant subjects. (3) The observed ratio of TK positive cells in the blood of pregnant women looks very similar to the earlier reported fetal:maternal cell ratio, estimated by other methods. ${ }^{1-3}$ Still, all these data only provide evidence that the cells found are fetal and experiments to prove conclusively that these TK positive cells are indeed fetal need to be done.

However, we describe a promising new approach specifically to detect fetal cells in the maternal circulation. Since in this assay the fetal cells exhibit a specific fluorescence, we think that it should be possible to enrich fetal cells through flow activated cell sorting. 
Experiments in this direction are currently under investigation in our laboratory.

Work in MH's laboratory is supported by the Austrian "Fonds zur Förderung wissenschaftlicher Forschung", by the Austrian "Nationalbank", and by the "Komission Onkologie" of the Medical Faculty of the University of Vienna. The authors wish to thank Thomas Soucek, Oliver Pusch, Gabriele Hölzl, and Elke Hengstschläger-Ottnad for helpful discussion and comments on the manuscript.

MARKUS HENGSTSCHLÄGER GERHARD BERNASCHEK University of Vienna, Obstetrics and Gynecology, Department of Prenatal Diagnosis and Therapy, Währinger Gürtel 18-20, A-1090 Vienna, Austria

1 de la Cruz F, Shifrin H, Elias S, et al. Prenatal diagnosis by use of fetal cells isolated from maternal blood. Am $\mathcal{f}$ Obstet Gynecol maternal blood

2 Adinolfi $M$. Non- or minimally invasive prenatal diagnostic tests on maternal blood samples or 96.

3 Gänshirt D, Garritsen HSP, Holzgreve W. Fetal cells in maternal blood. Curr Opin Obstet Gyne-

4 Hengstschläger $M$, Wawra E. Cytofluorometric assay for the determination of thymidine uptake and phosphorylation in living cells. Cytometry 1993;14:39-45.

5 Hengstschläger $M$, Wawra E. Cytofluorometric determination of thymidine kinase activity in a determination of thymidine kinase activity in a Cancer 1993;67:1022-5. 6 Hengstschläger $M$, Hengstschläger-Ottnad $E$, Pusch O, Wawra E. The role of p16 in the E2F-dependent thymidine
Oncogene 1996;12:1635-43.

7 Hengstschläger $M$, Pusch $O$, HengstschlägerOttnad E, Ambros PF, Bernaschek G, Wawra E. Loss of the p16/MTS1 tumor suppressor gene causes E2F-mediated deregulation of essential enzymes of the DNA precurso metabolism. DNA Cell Biol 1996;15:41-51.

8 Hengstschläger $M$, Pfeilstöcker $M$, Wawra $E$. Identification of leukemic cells in bone marrow assay. Br $\mathcal{F}$ Cancer 1996;73:1237-40.

\section{Segregation distortion of the CTG repeats at the myotonic dystrophy (DM) locus: new data from Brazilian DM families} dominant condition caused by a (CTG) expansion in the protein kinase (DMPK) gene locus on chromosome 19q. ${ }^{1-6}$ The clinical course is highly variable and may include frontal baldness, cataract, progressive muscular weakness and atrophy, male infertility, diabetes, and mental retardation. ${ }^{7}$ An intriguing question is how a disease which usually decreases reproductive fitness within a few generations has been maintained in the population with a relatively high prevalence, considering the rarity of new mutations. ${ }^{8}$ An attractive hypothesis which has been proposed to explain this observation is the occurrence of meiotic drive, ${ }^{9-11}$ that is, a sex specific distortion during meiosis (which may occur when there is a negative selection against one or more class of gametes or when transcervical cells. Prenat Diagn 1995;15:889col 1995;7:103-8. and blood samples by a new cytofluorometric

Myotonic dystrophy (DM) is an autosomal

they are unable to conjugate according to the usual meiotic pattern) favouring the transmission of larger repeat alleles. This mechanism would allow the replacement of the enlarged repeat alleles lost through negative selection, thus maintaining the prevalence of these conditions in the population.

Meiotic drive favouring the transmission of larger alleles in the DM locus through male meiosis was first suggested in 1994 for normal subjects ${ }^{9}$ and supported by Gennarelli et $a l^{10}$ in affected DM families. More recently, Chakraborty et al ${ }^{11}$ reported a preferential transmission of larger alleles in female meiosis but not in male meiosis, in contrast to the first two studies. These conflicting results show that the origin of meiotic drive is controversial.

In order to address this question, we have analysed the total number of affected versus normal subjects in 69 Brazilian families with $\mathrm{DM}$ and compared in the offspring of affected fathers versus affected mothers (1) the total proportion of affected versus norma offspring and (2) the sex ratio among affected and normal descendants.

As seen in table 1, there was no segregation distortion, that is, no significant difference in the expected mendelian ratios. The total proportion of affected versus normal offspring of maternal compared to paternal origin was 102 affected versus 107 unaffected born to DM mothers $\left(\chi^{2}=0.11, p=0.74\right)$ and 206 affected versus 200 normal born to affected fathers $\left(\chi^{2}=0.07, p=0.79\right)$. In addition, the analysis of the sex ratio showed that among the normal offspring of affected DM parents the proportion of male:female did not differ from expected ( 57 males: 50 females of maternal origin, $\chi^{2}=0.42, \quad \mathrm{p}=0.52 ; 97$ males: 103 females, $\chi^{2}=0.186, p=0.67$ )

Therefore no excess of DM patients was observed in Brazilian DM families as reported in Italian and Spanish DM pedigrees. ${ }^{10}$ One possible explanation is that in the present sample a proportion of subjects classified as normal, in particular in the older generations (and who are not available for DNA analysis), may carry the mutant allele.

However, among DM patients there were more affected male than female offspring, both of maternal ( 57 males: 45 females) and of paternal origin (117 males:89 females). This difference did not reach the level of significance $\left(\chi^{2}=1.41, p=0.24\right)$ for the offspring of affected mothers but was at the limit of significance $\left(\chi^{2}=3.80, p=0.05\right)$ for the offspring of affected fathers, probably owing to the sample size. Indeed, when the descendants of DM mothers were analysed together with those of DM fathers, the excess of affected males was statistically significant ( 174 males: 134 females, $\chi^{2}=5.19, p=0.02$ ).

These findings support the observation of Gennarelli et $a l^{10}$ who reported that the mutant allele is preferentially transmitted to sons than to daughters. Indeed, as seen in table 1 , when we analysed our data together with those published by these authors, there

Table 1 Proportion of affected and unaffected offspring born to DM parents

\begin{tabular}{|c|c|c|c|c|c|c|}
\hline \multirow{2}{*}{$\begin{array}{l}\text { Present study } \\
\left(\text { Gennarelli et al }{ }^{10}\right)\end{array}$} & \multicolumn{3}{|c|}{ DM fathers, $n=114$ (210) } & \multicolumn{3}{|c|}{ DM mothers, $n=78$ (178) } \\
\hline & $D M$ & Normal & Total & $D M$ & Normal & Total \\
\hline $\begin{array}{l}\text { Sons } \\
\text { Daughters } \\
\text { Total }\end{array}$ & $\begin{array}{r}117(166) \\
89(148) \\
206(314)\end{array}$ & $\begin{array}{r}97(105) \\
103(106) \\
200(211)\end{array}$ & $\begin{array}{l}214(271) \\
192(251) \\
406(525)\end{array}$ & $\begin{array}{c}57(112) \\
45(95) \\
102(207)\end{array}$ & $\begin{array}{c}57(71) \\
50(94) \\
107(165)\end{array}$ & $\begin{array}{r}114(183) \\
95(189) \\
209(372)\end{array}$ \\
\hline
\end{tabular}

Male DM versus normal offspring: maternal $\mathrm{p}=0.24$; paternal $\mathrm{p}=0.05$; total: maternal + paternal $\mathrm{p}=0.02$. Data from the present study are shown in bold and from Gennarelli et $a^{10}$ in parentheses. was a more significant excess of affected DM males; the total number of affected offspring (of both maternal and paternal origin) was 452 males: 377 females $\left(\chi^{2}=6.78, p=0.01\right)$. Also, in accordance with these authors, we observed that although the mutant allele is preferentially transmitted to male offspring by both sexes, the distortion reached a level of significance only in male to male transmission.

Interestingly, in a previous study of Brazilian DM families we had observed a significantly greater proportion of affected DM males than females, ${ }^{12}$ which had also been reported by others, ${ }^{13}$ a finding for which we had no biological explanation (except a bias of ascertainment). This observation was confirmed in the present study since among 878 subjects, there was a statistically significant excess of affected males as compared to affected females (237 males:174 females, $\chi^{2}=9.65, \mathrm{p}=0.002$ ), but no sex ratio distortion among unaffected relatives (234 males:233 females).

The present observation confirming that the mutant parental allele is significantly more often transmitted to sons than to daughters provides an explanation for the excess of affected males in DM families. It is noteworthy that the preferential transmission of the mutant allele to sons than to daughters independently of the sex of the transmitting parent, was also found in Brazilian MachadoJoseph disease families. ${ }^{14}$ These findings suggest that the mutated allele may have a selective advantage at the pre- or postzygotic level.

An interesting and unexpected finding is that although male infertility (but not female infertility) is one of the features reported for myotonic dystrophy, we have found in the present study that DM affected males have on average more children (406 offspring/114 fathers, mean=3.6 children per affected father) than DM mothers (209 offspring/78 mothers, mean $=2.7$ children per affected mother), although the proportion of affected patients who reproduced was similar for both sexes $(78 / 174=0.45$ females and $114 /$ $237=0.48$ males). A higher reproductive fitness in DM males (525 offspring/210 fathers, mean 2.5 child per father) than in DM females (372 offspring/178 mothers, mean 2.08 child per mother) was also reported in the study published by Gennarelli et $a .^{10}$ One possible explanation for this reproductive sex difference is that DM males are on average less severely affected than DM females. Indeed, in both studies the CTG expansion was significantly larger in the group of DM affected mothers (range from 66 to 1700 repeats in the present study, 90 to 2000 in the study of Gennarelli et $\mathrm{al}^{10}$ ) than in the group of affected fathers (ranging from 66 to 900 repeats in the present study, 54 to 1100 in the study of Gennarrelli et $a l^{10}$ ).

Interestingly, the estimated relative fitness of our DM males was also slightly greater than that observed in our normal population, as reported in the last census for the population of São Paulo (3.46 per male, age range 23-72). Therefore, it is tempting to speculate that if confirmed that DM men have a slightly higher relative fertility than the normal population associated with the observed preferential transmission of enlarged alleles to males, this would provide an explanation for maintaining the frequency of mutant alleles which are lost through negative selection. Other population studies will be very important to confirm this hypothesis. 